\title{
Motivational Interviewing to Engage Patients in Chronic Kidney Disease Management
}

\author{
Steve Martino \\ Department of Psychiatry, Yale University School of Medicine, West Haven, Conn., USA
}

\section{Key Words}

Behavior change $\cdot$ Chronic kidney disease $\cdot$ Motivational interviewing $\cdot$ Self-management

\begin{abstract}
Patients with chronic kidney disease (CKD) must manage numerous medical treatments and lifestyle changes that strain their treatment adherence. An important strategy to improve adherence is to activate the patients' motivation to manage their CKD. This article describes an approach for enhancing patients' motivation for change, called motivational interviewing (MI), a treatment that is increasingly being used in health care settings to counsel patients with chronic diseases. Its basic principles, techniques, empirical support, published applications for improving CKD patients' selfmanagement, and how to learn Ml are presented. Research is needed to determine the efficacy and mechanisms of $\mathrm{Ml}$ for CKD treatment as well as the development of innovative ways to deliver it to patients and train busy health care practitioners in the approach.

Copyright $\odot 2011$ S. Karger AG, Base
\end{abstract}

\section{Introduction}

Patients with chronic kidney disease (CKD) must manage numerous medical treatments and lifestyle changes to improve their health. They have to adhere to recommended diet and exercise routines, scheduled medical appointments, dialysis regimens, prescribed medications, and health monitoring activities to treat CKD and associated common comorbidities. As the disease progresses, these demands increase and patients' motivation to meet them typically waver. This diminished motivation may contribute to the patients' treatment nonadherence and disengagement from their practitioners. Helping CKD patients remain treatment adherent and engaged with their nephrology team is critical for improving their treatment outcomes and quality of life.

While treatment adherence for chronic illness involves many factors, such as patient demographics, treatment complexity and side effects, and availability of social and environmental supports [1], an important strategy to improve adherence is to activate the patients' motivation to manage their CKD [2]. This article describes an approach for enhancing patients' motivation for change, called motivational interviewing (MI) [3]. MI increasingly is being used in health care settings to counsel patients with chronic diseases such as CKD [4]. Its basic principles, techniques, empirical support, and published applications of MI for improving CKD patients' self-management are reviewed. The article concludes by describing how nephrology practitioners can learn the approach and future directions for studying MI for use with CKD patients.

\section{KARGER}

두 2011 S. Karger AG, Basel

Fax +41613061234 E-Mail karger@karger.ch www.karger.com www.karger.com/bpu
Dr. Steve Martino, Assoc. Prof.

Yale University School of Medicine, Department of Psychiatry

VA Connecticut Healthcare System, 950 Campbell Avenue (151-D)

West Haven, CT 06516 (USA)

Tel. +1 203932 5711, ext. 7418, Fax +1 203937 3472, E-Mail steve.martino@yale.edu 


\section{Principles of MI}

MI is 'a person-centered method of guiding to elicit and strengthen personal motivation for change' [5]. It originated for the treatment of addiction and has been adopted by many other practitioners across a wide array of fields to address the motivational issues underpinning their patients' behavioral problems. Typically, it is used as a brief intervention, though it is best construed as a style of communication that informs the way in which practitioners interact with their patients, particularly when motivational issues are salient. Four key principles, embodied in the REDS acronym, compose this style of interaction.

\section{Roll with Resistance}

Resistance in MI refers to patients' statements about what sustains their problematic behaviors. These expressions may be about the reasons for the behaviors ('I love fried foods') or the difficulties of trying to change them ('I don't know how to cook in any other way'). Resistance informs practitioners about their patients' dilemmas, thereby providing opportunities for addressing obstacles to change. Practitioners avoid adopting a confrontational, authoritative, warning, or threatening tone (all inconsistent with MI), which might cause patients to become even less engaged in treatment.

\section{Express Empathy}

Practitioners attempt to accurately understand their patients' dilemmas without judgment or criticism. Being able to listen carefully to what patients mean and reflect this back to them is a critical skill. Patients are more likely to explore their motivations for change and speak candidly when they feel comfortable with and understood by their practitioners.

\section{Develop Discrepancy}

Motivation for change often depends on the existence of a discrepancy between the patients' current behavior and important values or goals. In MI, practitioners reflect these discrepancies and explore how behavior change might help patients feel they are acting in accord with their preferred self-perceptions and aims. For example, a grandmother with end-stage renal disease who has taken pride in raising her granddaughter, but who has been physically inactive, might more likely participate in a recommended exercise program if she links this to her goal ('I will have more strength and energy for child rearing').
Support Self-Efficacy

Patients typically become more motivated when they believe they can change their behavior. When patients lack confidence, they often shy away from change. Practitioners look for opportunities to support the patients' self-efficacy by helping them recognize their personal strengths and available resources. Likewise, they pay particular attention to their patients' past successful change efforts that might inform how they approach their current challenges.

By embracing these principles, practitioners adopt a style of interaction that is (1) collaborative by demonstrating respect for the patients' ideas and goals and 'meeting them where they are at' motivationally, (2) evocative by eliciting from patients' statements that favor changing (called 'change talk'), and (3) supportive of the patients' autonomy and capacity to make decisions and initiate change. These three components embody the spirit of how practitioners interact with patients, a hallmark of MI.

\section{Techniques}

While MI is more of style or spirit of being with patients based on the above principles rather than a mere application of techniques, MI incorporates several techniques that operationalize how practitioners use MI. These techniques include fundamental strategies, sometimes called microskills (open questions, affirmations, reflections, and summaries), and direct methods for evoking change talk or handling resistance $[3,6]$. Practitioners attend to the balance of patient statements supporting or thwarting behavior change to gauge patient motivation and to adjust their use of MI techniques accordingly. Practitioners' capacities to elicit patient change talk and reduce resistant statements, with the aim of strengthening patients' commitment to change, are seen as necessary elements in MI $[6,7]$.

\section{Fundamental Strategies}

Open questions, affirmations, reflections, and summaries (the 'OARS') are the mainstay of all MI sessions. In particular, MI relies heavily on skilled use of reflective listening in which practitioners restate or paraphrase their understanding of what patients have said to express empathy, as well as to bring attention to ambivalence, highlight change talk, and explore and lessen resistance. Open questions encourage more patient discussion and may draw out motivations for change (e.g. 'What would 
be good about not smoking?'). Affirmations (i.e. acknowledgment of patients' strengths and change efforts) build collaboration between practitioners and patients and promote self-efficacy. Summaries provide opportunities for practitioners to demonstrate fuller understanding of the patients' experiences, collect multiple change talk statements, link discrepant statements that capture ambivalence, and shift focus to other behavioral areas (e.g. move from discussing diet to exercise). In general, when enhancing motivation, practitioners reflect more than question, use more open than closed questions, and genuinely affirm patients during each appointment.

\section{Direct Methods}

Direct methods for evoking patient change talk hinge on the capacity of practitioners to recognize how patients talk about change. Change talk, embodied in the acronym DARN-C, may involve a desire ('I don't want my kidney disease to get worse'), ability ('I can start monitoring my blood sugar better'), reason ('If I do what I have to do to get a kidney transplant, there is a chance I might make it to my 25th wedding anniversary'), need ('I want to be a role model for my daughter who also has kidney disease'), or commitment ('I will start the quit smoking program this week') [7]. Practitioners identify the extent to which patients express motivation in each of these areas, use their fundamental skills to support change talk revealed by the patient, and then in a goal-oriented fashion directly attempt to further develop or draw out more motivations for change. For example, patients who consistently note obstacles to healthier eating might be asked about past periods when they better managed their diet. Alternatively, these patients might be asked to look to the future at some time interval (e.g. 1 year from now) and consider where their lives are headed with continued poor dietary habits. MI uses many techniques designed to elicit these kinds of change promoting statements, with the aim of garnering a commitment to change once patients feel ready, willing, and able to change [6].

\section{Other Useful Techniques}

CKD treatment typically requires simultaneous attention to several behavioral risk factors, and this reality often is overwhelming to patients and to practitioners during any one appointment where time is limited. After discussing how patients have managed their CKD since their last visit, practitioners can use a simple agenda-setting chart in which they record the pertinent behavior change issues on paper and have patients indicate which of them they want to discuss [8]. The patients' priorities are then dovetailed with any pressing practitioner concerns to organize the conversation.

Education, advice-giving, and direction are commonplace in the treatment of CKD, particularly because practitioners' often have a natural tendency to try to fix patients' problems (referred to as the 'righting reflex'). When patients have not solicited professional input, however, they may not be receptive to it. Instead, practitioners ask permission to provide information or advice and employ an elicit-provide-elicit (or ask-tell-ask) technique in which practitioners (1) elicit from patients what they know about the topic being discussed, (2) provide information as needed, and (3) elicit from patients their reactions to the shared information. This technique promotes collaboration and reduces the chance patients experience their practitioners as giving them a lecture.

\section{Empirical Support}

Several meta-analyses [9-12] have examined the large body of MI research to determine if MI works across a wide range of problem areas (e.g. alcohol, tobacco, illicit drugs, diet/exercise, treatment adherence/engagement). The meta-analysis by Lundahl et al. [11] is the most recent and comprehensive one, including 119 studies that isolated the unique effect of MI. They showed that across problem areas MI exerted small yet clinically significant effects, consistent with effects produced by other behavior change interventions but in less time. MI also significantly increased patients' treatment engagement. The effects were durable, lasting up to one year. Studies examining how MI works have supported the underlying theory of MI. In brief, they have shown that practitioners who adhered to MI were more likely to have patients who responded with change talk, whereas those who were MI non-adherent experienced corresponding increases in resistant statements by their patients [13-15]. In turn, patients with increased in-session change talk had improved treatment outcomes (e.g. drinking, drug use, gambling) over the subsequent follow-up periods of up to one year $[7,13-20]$.

\section{Applications for CKD}

The nephrology literature has begun to report on applications of MI for CKD. Fisher et al. [21] described efforts to improve fluid management among 5 hemodialysis adult patients. Their intervention combined MI with 
cognitive behavioral therapy for up to twelve sessions and found that 3 of the 5 patients reduced both the mean interdialytic weight gain and the frequency in which they gained in excess of $3 \%$ of their dry weight. Van Vilsteren et al. [22] randomly assigned 96 sedentary hemodialysis patients to a low-to-moderate 12 -week renal rehabilitation exercise program with or without the addition of four MI sessions to improve exercise adherence. They showed that relative to the control condition, the addition of MI yielded significant increases in reaction time, lower extremity muscle strength, $\mathrm{Kt} / \mathrm{V}$, and three quality of life components. Others advocate for the use of MI as a method of engaging CKD patients to self-manage their own care [23]. A randomized trial of 793 CKD patients in nine Dutch hospitals is examining the extent to which the addition of a nurse practitioner trained to coach CKD patients with MI to adhere to treatment improves selfmanagement over the course of 5 years and the impact this has on cardiovascular morbidity and mortality, allcause mortality, renal function, vascular damage markers, and quality of life [24].

\section{Learning MI}

A variety of training resources exist to learn MI. These resources include textbooks, treatment manuals, training videotapes, a supervision toolkit, and an international training group called the Motivational Interviewing Network of Trainers. Many of these resources are accessible at www.motivationinterview.org. In addition, Miller et al. [25] have shown that practitioners' participation in intensive MI workshops plus post-workshop expert individual supervision based on direct observation (via recorded sessions) with performance feedback and individualized coaching results in substantial increases in practitioners' MI skills and in the frequency of patients' change talk. Feedback and coaching interventions typi- cally rely on MI performance rating scales [26, 27]. Workshops alone have not been found to produce these types of positive therapist training effects [28] and practitioners themselves generally are not accurate assessors of their own skills [29]. These findings underscore the importance of supervision and ongoing practice to develop MI skills. Using a train-the-trainer approach, on-site practitioners can be trained to conduct MI workshops and post-workshop supervision for their staff with good effect [30].

\section{Conclusion}

MI is a well-established empirically supported treatment to address behavioral problems. It has a clear set of principles and techniques that guide implementation and substantial training resources to prepare practitioners to conduct MI proficiently. MI has begun to be used with CKD patients. Well-conducted trials are needed to determine the efficacy and mechanisms of MI for CKD. Developing innovative ways to deliver MI to patients (e.g. computer-based intervention) and to teach practitioners the approach (e.g. interactive web-based and simulated trainings) will be important for busy health care settings.

\section{Acknowledgements}

National Institute on Drug Abuse grants (U10 DA13038, DA09241, DA023230) and National Institute of Mental Health grant (RMH0884772A) supported this article. The views expressed within it are those of the author and do not represent the views of NIDA or NIMH.

\section{Disclosure Statement}

The author has no conflict of interest to declare.

References

Julius RJ, Novitsky MA, Dubin WR: Medication adherence: a review of the literature and implications for clinical practice. J Psychiatr Pract 2009;15:34-44.

-2 Bodenheimer T, Wagner E, Grumbach K Improving primary care for patients with chronic illness: the chronic care model, part 2. JAMA 2002;288:1909-1914.

3 Miller WR, Rollnick S: Motivational Interviewing: Preparing People for Change, ed 2. New York, Guilford Press, 2002.
4 Rollnick S, Miller WR, Butler CC: Motivational Interviewing in Health Care: Helping Patients Change Behavior. New York, Guilford Press, 2008.

5 Miller WR, Rollnick S: Ten things that motivational interviewing is not. Behav Cogn Psychother 2009;37:129-140.

6 Miller WR, Rose GS: Toward a theory of motivational interviewing. Am Psychol 2009; 64:527-537. 
7 Amhreim P, Miller WR, Yahne CE, Palmer M, Fulcher L: Client commitment language during motivational interviewing. J Consult Clin Psychol 2003;71:862-878.

$\checkmark 8$ Rollnick S, Heather N: Negotiating behavior change in medical settings: the development of brief motivational interviewing. J Ment Health 1992;1:25-38.

9 Burke BL, Arkowitz H, Menchola M: The efficacy motivational interviewing: a metaanalysis of controlled trials. J Consult Clin Psychol 2003;71:843-861.

10 Hettema J, Steele J, Miller WR: Motivational interviewing. Annu Rev Clin Psychol 2005; 1:91-111.

- 11 Lundahl BW, Kunz C, Brownell C, Tollefson D, Burke B: Meta-analysis of motivational interviewing: twenty five years of empirical studies. Res Soc Work Pract 2010;20:137160.

12 Vasilaki E, Hosier S, Cox W: The efficacy of motivational interviewing as a brief intervention for excessive drinking: a meta-analytic review. Alcohol Alcohol 2006;41:328335.

$\checkmark 13$ Moyers TB, Martin T: Therapist influence on client language during motivational interviewing sessions: support for a potential causal mechanism. J Subst Abuse Treat 2006; 30:245-251.

-14 Moyers TB, Martin T, Christopher PJ, Houck JM, Tonigan JS, Amrhein PC: Client language as a mediator of motivational interviewing efficacy: where is the evidence? Alc Clin Exp Res 2007;31(suppl 3):40-47.
15 Moyers TB, Martin T, Houck JM, Christopher P J, Tonigan JS: From in-session behaviors to drinking outcomes: a causal chain for motivational interviewing. J Consult Clin Psychol 2009;77:1113-1124.

16 Apodaca TR, Longabaugh R: Mechanisms of change in motivational interviewing: a review and preliminary evaluation of the evidence. Addiction 2009; 104:705-715.

17 Baer JS, Beadnell B, Garrett SB, Hartzler B, Wells EA, Peterson PL: Adolescent change language within a brief motivational intervention and substance use outcomes. Psychol Addict Behav 2008;22:570-575.

18 Gaume J, Gmel G, Faouzi M, Daeppen J: Counselor skill influences outcomes of brief motivation interventions. J Subst Abuse Treat 2009;37:151-159.

19 Hodgins DC, Ching LE, McEwen J: Strength of commitment language in motivational interviewing and gambling outcomes. Psychol Addict Behav 2009;23:122-130.

20 Strang J, McCambridge J: Can the practitioner correctly predict outcome in motivational interviewing? J Subst Abuse Treat 2004;27: 83-88.

21 Fisher L, Cairns HS, Amir-Ansari B, Scoble JE, Chalder T, Treasure J: Psychological intervention in fluid management. Palliat Support Care 2006;4:419-424.

22 van Vilsteren MCBA, de Greef MHG, Huisman RM: The effects of a low-to-moderate intensity pre-conditioning exercise programme linked with exercise counseling for sedentary haemodialysis patient in The Netherlands: results of a randomized clinical trial. Nephrol Dial Transplant 2005;20:141146.

23 McCarley P: Patient empowerment and motivational interviewing: engaging patients to self-manage their own care. Nephrol Nurse J 2009;36:409-413.
24 van Zuilen AD, Wetzels JFM, Bots ML, Blankestijn PJ: MASTERPLAN: study of the role of nurse practitioners in a multifactorial intervention to reduce cardiovascular risk in chronic kidney disease patients. J Nephrol 2008;21:261-267.

25 Miller WR, Yahne CE, Moyers TB, Martinez J, Pirritano M: A randomized trial of methods to help clinicians learn motivational interviewing. J Consult Clin Psychol 2004;72: 1052-1062.

26 Martino S, Ball SA, Ball SA, Nich C, Frankforter TL, Carroll KM: Community program therapist adherence and competence in motivational enhancement therapy. Drug Alcohol Depend 2008;97:37-48.

$\checkmark 27$ Moyers TB, Martin T, Manuel JK, Hendrickson SML, Miller WR: Assessing competence in the use of motivational interviewing. J Subst Abuse Treat 2005;28:19-26.

28 Walters ST, Matson SA, Baer JS, Ziedonis DM: Effectiveness of workshop training for psychosocial addiction treatments: a systematic review. J Subst Abuse Treat 2005;29:283293.

29 Martino S, Ball SA, Nich C, Frankforter TL, Carroll KM: Correspondence of motivational enhancement treatment integrity ratings among therapists, supervisors, and observers. Psychother Res 2009;19:181-193.

30 Martino S, Ball SA, Nich C, Canning-Ball M, Rounsaville BJ, Carroll KM: Teaching community program clinicians motivational interviewing using expert and train-the-trainer strategies. Addiction, Epub ahead of print. 